\title{
The formation of flashbulb memories
}

\author{
MARTIN A. CONWAY and STEPHEN J. ANDERSON \\ University of Bristol, Bristol, England \\ STEEN F. LARSEN \\ University of Aarhus, Aarhus, Denmark \\ C. M. DONNELLY and M. A. MCDANIEL \\ Purdue University, West Lafayette, Indiana \\ A. G. R. MCCLELLAND and R. E. RAWLES \\ University College London, London, England \\ and \\ R. H. LOGIE \\ University of Aberdeen, Aberdeen, Scotland
}

\begin{abstract}
A large group of subjects took part in a multinational test-retest study to investigate the formation of flashbulb (FB) memories for learning the news of the resignation of the British prime minister, Margaret Thatcher. Over $86 \%$ of the U.K. subjects were found to have FB memories nearly 1 year after the resignation; their memory reports were characterized by spontaneous, accurate, and full recall of event details, including minutiae. In contrast, less than $29 \%$ of the non-U.K. subjects had FB memories 1 year later; memory reports in this group were characterized by forgetting, reconstructive errors, and confabulatory responses. A causal analysis of secondary variables showed that the formation of FB memories was primarily associated with the level of importance attached to the event and level of affective response to the news. These findings lend some support to the study by R. Brown and Kulik (1977), who suggest that FB memories may constitute a class of autobiographical memories distinguished by some form of preferential encoding.
\end{abstract}

In this paper we present findings from a large-scale multinational test-retest study of flashbulb (FB) memories for the abrupt and unexpected resignation of the British prime minister, Margaret Thatcher. The resignation provided a unique opportunity to examine FB memories (R. Brown \& Kulik, 1977) in groups of U.K. and non-U.K. nationals. The primary purpose of the study was to investigate the determinants of FB memories, and measures were taken of the variables affecting encoding and rehearsal. We planned to explore the structural relations between encoding factors such as affect, prior knowledge, and consequentiality, and the postencoding factor of rehearsal, for both FB and non-FB memories. Before turning to details of the study, we first consider R. Brown and Kulik's original proposals regarding the formation of FB memories and then review other studies of FB memories.

This research was supported by each of the institutions to which the individual authors are affiliated. Additional data were collected by Peter Hayes, Cilla Morris, Peter Morris, and Stephen Dewhurst. Susan Gathercole and Philip Levy advised us on parts of the analyses and Gillian Cohen commented on an earlier draft of the paper. We thank them for their assistance. Address correspondence to M. A. Conway, University of Bristol, Department of Psychology, 8 Woodland Road, Bristol, BS8 1TN England.

\section{Consequentiality, Surprise, and the Formation} of Flashbulb Memories

Throughout the present account of FB memories, we distinguish between an original event, such as the assassination of a president, and one's personal circumstances when learning of the original event, which we will refer to as the reception event (Larsen, 1988). Two critical components in R. Brown and Kulik's (1977) model of FB memories are that the original event should be both surprising and consequential. Indeed, the central tenet of $\mathrm{R}$. Brown and Kulik's model is that an individual will have a detailed and durable FB memory to the extent that they experience surprise and perceive a news item to be consequential. R. Brown and Kulik did not measure the levels of surprise associated with the 10 events they sampled, although because these were generally unexpected public events (i.e., the assassination of various political leaders), it seems reasonable to assume that the news of these events probably was surprising. Brown and Kulik did, however, explicitly assess the perceived consequentiality of the news events and instructed their subjects that "Probably the best single question to ask yourself in rating consequentiality is "what consequences for my life, both direct and indirect, has this event had?' ' (R. Brown \& Kulik, 1977, p. 82). They further instructed their sub- 
jects to consider how their lives might have progressed if the original event had not occurred. Finally, they acknowledged that "personal" consequentiality is highly related to the personal importance that an individual attaches to an event.

In addition to this self-assessed measure of consequentiality/importance, R. Brown and Kulik (1977) also selected their news events so that some of them would be consequential and/or important for some of their subjects, but not for others. They found that when an event was consequential or important for one group, it was associated with a comparatively high incidence of FB memories; however, the same event, when judged lower in consequentiality/importance by another group, was found to be associated with a reliably lower incidence of FB memories. For example, the assassination of Martin Luther King was associated with a high incidence of FB memories among black North Americans, compared with a significantly lower incidence for white North Americans. Compare this with FB memories for the attempted assassination of George Wallace, in which $50 \%$ of the white North Americans had FB memories compared with $25 \%$ of the black North Americans. For events of equal significance to both groups, such as the assassination of President John F. Kennedy, there were no differences in the generally high incidence of FB memories. Thus, R. Brown and Kulik established that personal consequentiality or personal importance of a news event is a critical determinant of FB memory formation. Finally, Rubin and Kozin (1984), in a wider survey of highly vivid memories, found that increased personal importance was closely associated with increased memory clarity, lending additional support to R. Brown and Kulik's emphasis on consequentiality/importance as one of the critical variables in FB memory formation.

In summary then, according to R. Brown and Kulik's (1977) account of FB memory formation, the original news event must be (optimally) surprising and must entail personal consequences. If these conditions are met, then a detailed and stable memory of the reception event is formed. But how detailed? R. Brown and Kulik found that their subjects frequently recalled where they were, who they were with, what they were doing, how they felt, the reactions of others, and what happened after the news was announced. Retention of this level of detail is in itself unusual, because such details, even for events of national significance, are usually rapidly forgotten over retention intervals measured in days or weeks (Larsen, 1992). The retention intervals in R. Brown and Kulik's study were on a scale of years and decades. They also found that many of their subjects frequently retained knowledge of apparently trivial details from a reception event, such as the "feel" of the soles of a particular pair of shoes, the brand name of a discarded pack of cigarettes, and so forth. However, they also noted that by no means were all the details from a reception event retained. For example, in an account of his own FB memory for learning of J.F.K.'s assassination, R. Brown states that he had been on the telephone to the dean's secretary about some "forgotten" business. Thus, although FB memories for the reception events of learning surprising and consequential or important news are unusually detailed and durable for that class of reception event (see Larsen, 1992), they are by no means complete records of such events.

\section{Recent Studies of Flashbulb Memories}

Studies of the FB memory concept must, then, focus on memory for events that are highly surprising and consequential or important. Several researchers (Bohannon, 1988; Neisser \& Harsch, 1992; McCloskey, Wible, \& Cohen, 1988), who have generally been critical of the FB memory concept, have focused on FB memories of the space shuttle Challenger disaster. McCloskey et al. and Neisser and Harsch used test-retest designs in which a group of subjects are tested close to the time of the reception event, and then a subset of these subjects are retested after a retention interval of months or years. These subjects typically provide a free description of the reception event and then answer specific questions as to who they were with, what they were doing, location, time of day, and so on. The critical measure is consistency in memory details over the two test sessions. Very high consistency is an indication of a basically accurate FB memory formed during or shortly after the reception event, which is accessed on both test occasions. Deviation from this very high level of consistency in repeated memory descriptions is construed as denoting incomplete memories that have not endured over time, and which are not FB memories.

McCloskey et al. (1988) found that the majority of a group of 29 subjects retested over a 9-month retention interval actually had FB memories. From their Table 1 (McCloskey et al., 1988, p. 173), it appears that at least $89 \%$ of their subjects could, 9 months later, accurately recall location, activity, source of the news, and their reaction (first thoughts) upon first learning of the Challenger disaster. In contrast, Neisser and Harsch (1992) found that very few of their 44 subjects had FB memories after a retention interval of 32 to 34 months. Bohannon (1988), in a large-scale FB memory study of the Challenger disaster, sampled two independent groups of subjects-one close to the date of the disaster and another 8 months later. As with Neisser and Harsch, very few of Bohannon's subjects actually had FB memories of the disaster. If we consider only those subjects who could recall the source of the news, ongoing activity, and place (a very lenient criteria for coding an FB memory), then it appears that less than $35 \%$ of Bohannon's subjects had detailed and durable memories (see Bohannon, 1988, Table 2, p. 186).

One feature that is common to all three of these studies is that the surprise value and consequentiality/importance levels of the Challenger disaster were assumed rather than measured. But what if these assumptions were unwarranted? Consider the following. Suppose that, for the subjects in the studies by Neisser and Harsch (1992) and Bohannon (1988), the Challenger disaster was only mildly 
surprising and of little or no consequence or personal importance. This then would completely explain why such a low incidence of FB memories was observed in these studies-the levels of surprise and consequentiality that are critical to FB memory formation were not reached during the reception event and, therefore, no FB memories were formed. A similar argument can be applied to those few non-FB memory subjects in McCloskey et al.'s (1988) study. Moreover, for those subjects who did show evidence of detailed and durable memories in all three studies, presumably, the levels of surprise and consequentiality at encoding passed some critical threshold and FB memories were formed.

It is even possible that these cross-study differences in the incidence of FB memories reflect group differences that are similar to those explicitly assessed by R. Brown and Kulik (1977). In McCloskey et al. (1988), the subject sample of faculty staff must have been considerably older than the undergraduate subjects used by Neisser and Harsch (1992) and Bohannon (1988). Perhaps for the older group of subjects the space program was generally of high personal relevance and a more integral part of their personal past. For the younger subjects, however, the space program may have been low, or lower, in personal relevance, more remote, and less obviously a part of shared cultural experience. If this were the case, then it might be expected that the Challenger disaster would be perceived to be more consequential by older than by younger subjects, and so a higher incidence of FB memories would be present in the former than in the latter group. Whatever the case, because measures of surprise and consequentiality/importance were not taken, FB memory findings from the Challenger studies are ambiguous. This event may have been surprising and consequential for some subjects but not for others, and hence the pattern of disparate findings across studies.

R. Brown and Kulik (1977) proposed that levels of surprise, consequentiality/importance, and affect are probably interrelated to at least some degree. Thus, a measure of intensity of emotional reaction to learning of the Challenger disaster might suffice as an indirect indicator of levels of surprise and consequentiality/importance. McCloskey et al. (1988) did not take a direct measure of intensity of affect and, although Neisser and Harsch (1992) derived such a measure, it was based on the number of negative-emotion words that a subject employed when answering the question "How did you feel about the news?"' Bohannon (1988) did, however, employ a direct measure of emotional intensity in the form of a 5point rating scale and found that subjects reported only moderate levels of affect in response to learning the news of the disaster. This finding is revealing and demonstrates that, in a large sample of subjects $(n=687)$, news of the Challenger disaster did not cause widespread and strong emotional reactions. To the extent that surprise, consequentiality/importance, and affect are all associated (i.e., share common variance), this finding implies that the Challenger disaster would, at best, have generated only moderate levels of surprise and consequentiality/importance and, therefore, a correspondingly low incidence of FB memories is to be expected.

In contrast to the studies on the Challenger disaster, other FB memory studies have been attempts to directly assess the critical variables of surprise and consequentiality/importance. Christianson (1989) conducted a test-retest study $(n=36)$ of the assassination of the Swedish prime minister, Olof Palme. Subjects completed an FB memory questionnaire, similar to those described previously, 6 weeks after the assassination and again 52 to 54 weeks later. In addition to providing memory details, the subjects also rated how "upsetting" and surprising they had found the news. It was found that the subjects generally had a negative emotional reaction to the news and that all of the subjects were extremely surprised. On a "lenient" scoring criteria (i.e., a subject's response was "basically" rather than "exactly" correct), it was found that over $90 \%$ of Christianson's subjects had FB memories. However, when a stricter scoring criteria was used, which required the subjects to be exactly correct in their retest responses, the incidence of FB memories fell to just over $50 \%$. The secondary variables of emotion and surprise were not generally related to the incidence of FB memories, with the exception that, on the lenient scoring criteria, the subjects who were most surprised were reliably more consistent in their memory reports than were those who were somewhat less surprised.

One problem with this study was that Christianson's subjects did not judge the consequentiality/importance of the event, and so it is not known whether or not this crucial factor influenced FB memory formation. For instance, a person may have been "shocked and surprised" (see Neisser \& Harsch, 1992) by the news of Palme's murder, but the event may nonetheless have been of little personal consequence. If this was the case for Christianson's subjects, then of course FB memory formation would be attenuated. A much more important problem relates to the sensitivity of the measures of intensity of emotion and surprise. Recall that the subjects were first questioned only 6 weeks after learning of the news; therefore, the sensitivity of these measures crucially depended upon their ability to accurately recall the degree to which they were upset and surprised. If the subjects could not do this, then their judgments would not be accurate and would be unlikely to be related to memory consistency. In connection with this, Pillemer (1984) found that ratings of affect and surprise taken 6 months after an FB memory event were unrelated to memory consistency, which strongly suggests that such measures must be taken reasonably close to the time of the event. In Pillemer's study, ratings taken within 1 month proved to be reliably associated with memory consistency. The 6-week delay in Christianson's study may, then, have been associated with a lowering of the effectiveness of these rating scales.

The study that comes closest to directly and effectively assessing R. Brown and Kulik's (1977) FB memory con- 
cept was reported by Pillemer (1984). Pillemer investigated subjects' memories for the attempted assassination of President Ronald Reagan by having a single group $(n=44)$ complete an FB memory questionnaire 1 month after the shooting and again $6 \frac{1}{2}$ months later. Apart from completing free-memory descriptions of the reception event and answers to probe questions, the subjects also completed a series of rating scales assessing surprise, consequentiality, emotion, and opinions of Reagan. Pillemer found that the majority of his subjects had FB memories and that memory descriptions were highly consistent over the two testing sessions. Moreover, the only two variables found to be reliably and positively associated with FB memories were emotion and surprise. The subjects' ratings indicated only moderate levels of emotion and surprise. In contrast, consequentiality, which was assessed by a question asking the subjects to judge the "impact" of the news, was very low and unrelated to memory consistency. It is far from clear that ratings of "impact" assess R. Brown and Kulik's notion of personal consequences; nevertheless, it would appear that the attempted assassination of President Reagan, although low in impact, gave rise to the formation of FB memories and that this process was closely associated with affect and surprise so that the more intense the experience of affect and surprise, the more consistent the memory.

\section{Flashbulb Memories for the Resignation of Prime Minister Margaret Thatcher}

In the preceding section it was shown that a number of methodological problems specific to individual studies have prevented the direct evaluation of the process of FB memory formation as originally proposed by $\mathrm{R}$. Brown and Kulik (1977). More generally, past researchers (with the exception of Bohannon, 1988) have employed only small groups of subjects. This is a problem because it precludes the use of multivariate analyses, which are essential if latent constructs such as FB memories, affect, consequentiality/importance, rehearsal, and the relations between such constructs are to be assessed. Finally, previous researchers have not followed R. Brown and Kulik's lead of employing different groups of subjects who can be compared for memory consistency across different levels of surprise, consequentiality/importance, and so forth. In the present study, we attempted to rectify these problems by sampling large groups of subjects of different nationalities within 14 days of the target event and again 11 months later. We based the design of our study on Pillemer (1984) and included scales that directly assessed the importance of the event both personally and nationally, affect, prior knowledge of politics and orientation to the event, and levels of rehearsal. The target event was the resignation of Mrs. Thatcher from the post of prime minister, which was announced on Thursday, November 22, 1990, at approximately 10:30 a.m. ${ }^{1}$ It was predicted, following R. Brown and Kulik, that higher affect and consequentiality (hereafter referred to as im- portance) would be closely associated with FB memory formation.

\section{METHOD}

\section{Design}

The main variable was nationality of the subject samples; there were two levels. The U.K. group consisted of subjects sampled from various sites in the United Kingdom, and the non-U.K. group consisted of subjects who were not British and who were not residents of the United Kingdom at the time of the resignation. All the subjects completed an FB memory questionnaire (FBQ) within 14 days of the resignation and again after a retention interval of 11 months. The main measure was each subject's FB memory score, calculated from their responses to the FBQ. In two sets of secondary measures we examined the aspects of encoding and rehearsal. The encoding measures were further subdivided into sections in which a number of variables assessed affect, importance, and prior knowledge. Order of presentation of these sections on the FB memory questionnaire was the same for all the subjects. At the 11-month test interval, confidence ratings for some of the FBQ items were also collected. Part 1 of the questionnaire required a description of the reception event, Part 2 assessed specific aspects of the reception event, including original affect and subsequent rehearsal, and the purpose of Part 3 was to gather information on importance and prior knowledge.

\section{Subjects}

Three hundred and sixty-nine subjects took part- 215 in the U.K. group and 154 in the non-U.K. group. ${ }^{2}$ The U.K. group was recruited from undergraduate populations at the universities of Aberdeen, Lancaster, and London. The majority of subjects (over $90 \%$ ) were first-year psychology undergraduates, and of these over $70 \%$ were tested as part of a class exercise. Other undergraduates were contacted by internal mail. The non-U.K. group was recruited from North America (Purdue University), Denmark (Aarhus University), and from a variety of other countries. The North American sample constituted $95 \%$ of this group, the Danish sample $4 \%$, and the others $1 \%$. The non-U.K. group was primarily composed of first-year psychology undergraduates who were contacted and tested in the same way as the U.K. group. The majority $(80 \%)$ of both U.K. and nonU.K. subjects were tested within 10 days of the resignation, and the remainder were tested within 14 days. The subjects were retested during late October and early November of 1991, between 333 and 350 days after the resignation. The testing of the U.K. and nonU.K. groups was evenly distributed over this 27 -day interval.

\section{The Flashbulb Memory Questionnaire}

The FBQ was modeled on a similar questionnaire designed by Pillemer (1984); Appendix A shows the composition of the FBQ used in the present study. ${ }^{3}$ The first question on the FBQ required the subjects to respond "yes" or "no" to the question "Do you recall the circumstances in which you first heard of the resignation of Margaret Thatcher?" The subjects who responded "yes" then went on to complete all parts of the FBQ. Those who responded "no" skipped the memory description in Part 1, answered any questions they could in Part 2 (guessing where necessary), and answered all the questions in Part 3. For the memory description in Part 1, the subjects were instructed to write a short description of the reception event-about a paragraph in length. Following this, space was provided for them to list any other memories that they had of the time that they had learned of the resignation. The subjects were not given any direction about the type of memories that might come to mind, and were simply asked to write a short description of the content of any memories that spontaneously occurred to them. ${ }^{4}$ 


\section{Procedure}

All the subjects were provided with a copy of the FBQ either directly by the experimenter or in the mail with an accompanying letter, which requested that they complete the enclosed questionnaire and not discuss the contents or their answers with other students. The front cover of the FBQ contained an introduction that informed the subjects that the study focused on memory for public events and, in particular, on memory for one's personal circumstances when learning the news of a major public event. The example of the assassination of John F. Kennedy was provided and it was explained to the subjects that many people over the age of 40 years could recall who they were with, what they were doing, and where they were when they first heard the news of the assassination. The subjects were told that a major public event that had recently occurred in Britain was identified on the following page and that their task was to try to recall their personal circumstances when they had learned of this news. The subjects then continued on with the various sections of the questionnaire, taking between 20 and $30 \mathrm{~min}$ to complete it. At retest they were informed that they had completed a similar questionnaire 1 year previously and that the current questionnaire was a follow-up to the earlier test. Finally, a small subsample of subjects, all Lancaster University undergraduates, were tested for a third time in February 1993, 26 months after Thatcher's resignation. Thirty-three subjects, about 9\% of the total retest sample, and all Lancaster University finalyear psychology students, took part in this third phase of the study. These subjects again completed the retest FBQ.

\section{RESULTS}

The results are divided into four sections in the following text. In the first section, the scoring of FB memories and the variables selected for analysis are described. Analyses of the incidence and accuracy of FB memories are reported next. In the third section, analyses of the secondary variables are reported, and in the fourth section we report regression analyses and a causal model of FB memory formation.

\section{Scoring Flashbulb Memories}

In scoring the memory data, we followed a procedure developed by Neisser and Harsch (1992). In this procedure a memory attribute such as "place" is assigned a score of 0,1 , or 2 . A score of 0 indicates that the subject either forgot the attribute (i.e., did not complete that question in the FBQ) or entered a different attribute at retest (e.g., originally answered "in my office at work" and at retest responded "watching TV in my living room at home'). A score of 1 denotes a basically, but not exactly, correct response. In this case, the subject might originally respond with "in my office at work" and at retest with "at work." A score of 2 indicates that the subject is $e x$ actly correct. In this case, the original and retest responses mention identical information and the retest response includes all the information originally mentioned, and may also include additional new information. The advantage of this system is that memories are graded for consistency and, by implication, accuracy.

Memory scores were compiled from five memory attributes corresponding to those identified in R. Brown and Kulik (1977) and in other studies as being critical attributes of FB memories: memory description as well as an- swers to the questions for people, place, activity, and source. The subjects were assigned a score of 0,1 , or 2 for each attribute, according to the correspondence between their original and retest responses. For each subject, the scores were assigned separately by two judges and correlation coefficients between judges were computed. For the five attributes, the correlations were all higher than $r>.92$ and the comparatively few discrepancies were resolved in discussion with the first author.

Using this scoring procedure, memory scores fall on a scale of $0-10$. Throughout the remainder of this paper, we proportionalize these so that memory scores are expressed as scores between 0 and 1 . Scores of .9 and 1 are classified as FB memories; these scores indicate that a subject was either exactly consistent in the majority of his/her memory attributes or was exact on all but one attribute, for which the answer was slightly more general at retest than test. ${ }^{5}$ Memory scores of less than .9 indicate memories that are not considered FB memories. In general, scores in the range of .1-.8 represent memories for which some information has been omitted (forgotten). However, scores of 0 represent memories that have either been forgotten or that were radically inconsistent over time. Memory descriptions, illustrating the scoring scheme, are shown in Appendix B.

In the analyses of the incidence of FB memories across nationalities, we used the categorization of memory scores into FB memories and non-FB memories. There are two sets of secondary variable data-one set collected within 14 days of the resignation and the second set collected approximately 11 months later. The secondary variables, relating to the factors influencing encoding, are represented in the correlational analyses by the responses given on the original test; this is because these responses are closest in time to the reception event. The secondary variables, relating to rehearsal, are represented by the various ratings of rehearsal (see Appendix A) collected 11 months after the resignation. We reasoned that because rehearsal is a process that develops over time, the ratings at the 11-month interval were likely to be more representative of this process than those taken closer to the event. $^{6}$

\section{The Incidence and Accuracy of Flashbulb Memories}

A striking difference in the incidence of FB memories across the two groups was observed; $85.6 \%$ of the U.K. group had memory scores classified as FB memories compared with an FB memory rate of $28.6 \%$ in the non-U.K. group. These differences in overall memory consistency were analyzed in a $2 \times 2$ chi-square, in which nationality (U.K. vs. non-U.K.) and memory type (FB vs. nonFB) were used as grouping factors. A significant chisquare $(1, N=369)$ of $123.5, p<.001$, was observed, indicating that frequency of FB memories varied with group. For the U.K. group, 184 subjects were classified as having FB memories compared with 31 who did not, whereas the corresponding frequencies for the non-U.K. group were $\mathrm{FB}=44$ and non-FB $=110$. Thus, the in- 


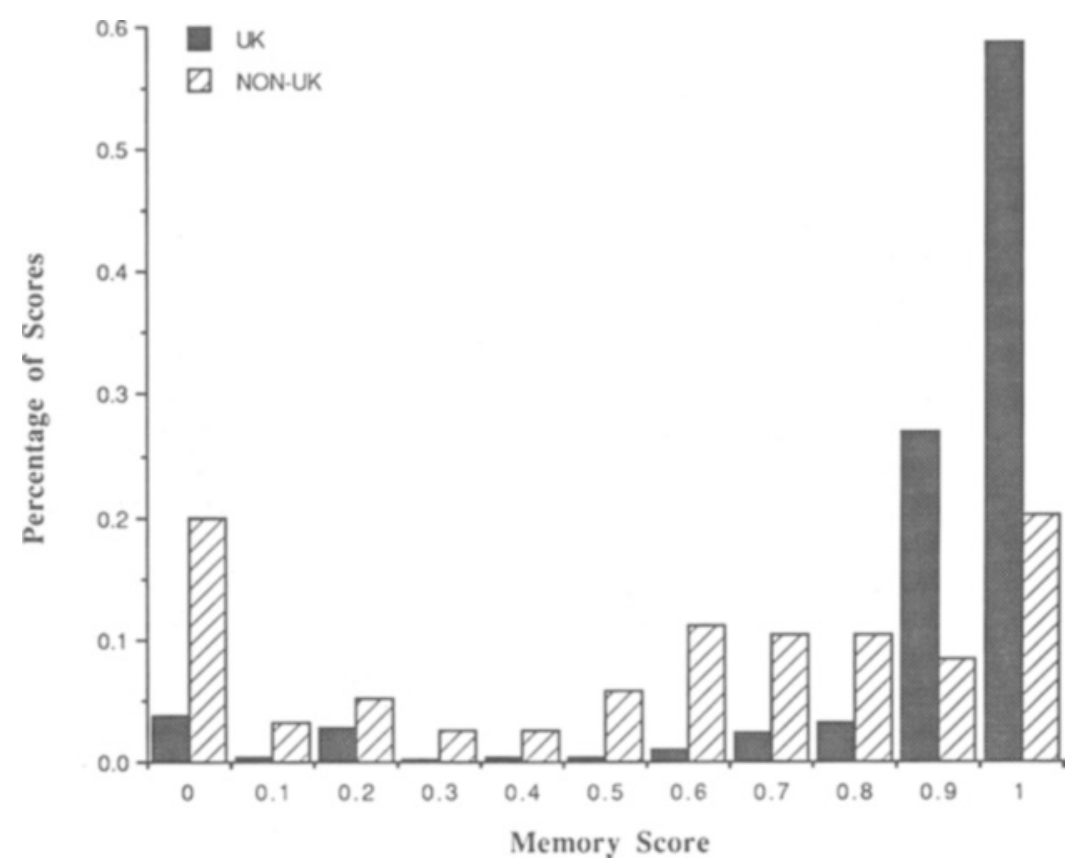

Figure 1. The distribution of FB memory scores by nationality.

cidence of FB memories was approximately three times greater in the U.K. group; this is illustrated in Figure 1, which shows the distribution of memory scores within the two groups.

First, consider the U.K. group. Comparatively few memories occur below the .9 category on the scale, and by far the largest number of memories occur in the " 1 ", category. This shows that the content of the majority of the U.K. subjects' FBQ memory responses 11 months after the event exactly corresponded to their earlier responses, which were given within 2 weeks of the reception event. Note that examination of the memory description responses did not reveal identical linguistic forms of the two descriptions. In less than $1 \%$ of cases was there a striking correspondence between the actual words used in the descriptions and the order of presentation of information, suggesting that the subjects at retest did not recall their earlier description, but in fact recalled a memory of the actual reception event. For the non-U.K. group, the distribution of memories across the memory score range is quite different; substantial numbers of memories fall in the categories $0-.8$. These memories are, perhaps, more typical of autobiographical memories in general, in which after a retention interval of some months only fragmentary knowledge of the event characteristics are retained (see Conway \& Rubin, 1993).

In order to explore the retention of memory attributes for FB and non-FB memories, we conducted a mixedmodel analysis of variance (ANOVA) ${ }^{7}$ on the scores assigned to each attribute. In this analysis, memory attributes were treated as a within-subjects variable with five levels (description, people, place, activity, and source); scores ranged from 0 to 2 on each individual attribute. Nationality (U.K. and non-U.K.) and FB memory (FB and non-FB) formed between-subjects variables. Following R. Brown and Kulik (1977), we reasoned that a subject either did or did not have an FB memory and that FB memories were qualitatively different from non-FB memories due to privileged encoding or some other set variables influencing their formation. Hence, we decided to treat the FB memory as a grouping factor in this analysis. However, no main effects or interactions are reported because of a ceiling effect in the FB memory group, which was a direct consequence of the categorization of memories into $\mathrm{FB}$ and non-FB. Instead, the analyses focus on comparisons between the pattern of accuracy scores for the memory attributes within the FB and non-FB memory groups.

In Figure 2, the mean accuracy scores for each of the five memory attributes are shown for both the FB and nonFB memory groups. The subjects with FB memories were, in the main, exactly correct on all memory attributes. Only the scores for description differed reliably from each of the other scores [the averaged contrast ${ }^{8}$ was $\left.F(1,908)=113, M S_{\mathrm{e}}=6.3, p<.001, \epsilon^{2}=.091\right]$. As mentioned, this was because the subjects tended to be slightly more general and brief in their retest memory descriptions. For the non-FB group, description differed reliably from people $\left[F(1,560)=24.6, M S_{\mathrm{e}}=10.3, p<\right.$ $\left..001, \epsilon^{2}=.017\right]$ and activity $\left[F(1,560)=22.8, M S_{\mathrm{e}}=\right.$ $\left.9.6, p<.001, \epsilon^{2}=.015\right]$. The attribute of people differed reliably from place $\left[F(1,560)=33.5, M S_{\mathrm{e}}=14.1\right.$, $\left.p<.001, \epsilon^{2}=.057\right]$ and source $[F(1,560)=29.4$, $\left.M S_{\mathrm{e}}=12.3, p<.001, \epsilon^{2}=.051\right]$. However, neither 


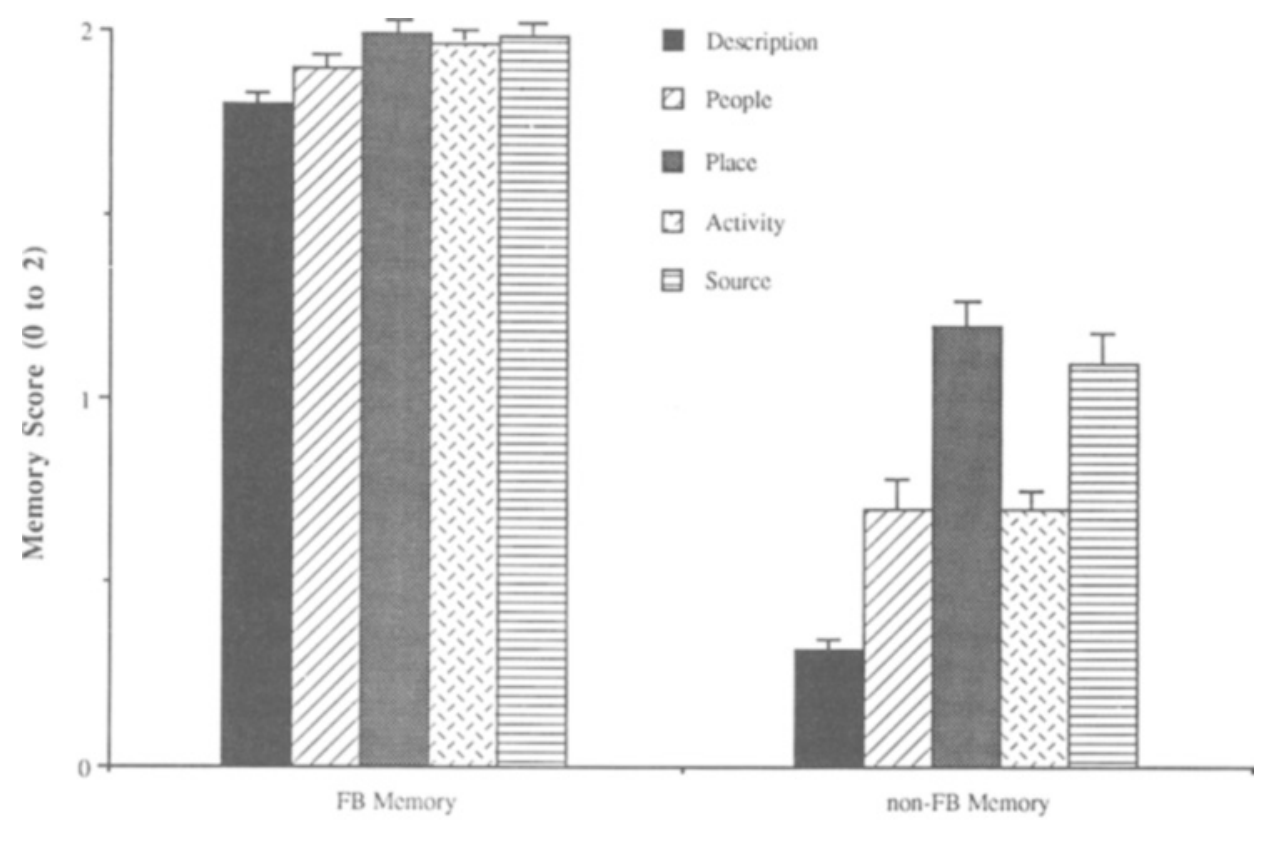

Memory Type

Figure 2. Accuracy scores of five memory attributes for the FB and non-FB memory groups.

people and activity nor place and source differed reliably ( $F<1$ in both cases).

The means in Figure 2 show that, for the non-FB memory group, memory for the reception event of learning of Margaret Thatcher's resignation fragmented over time. The ability to provide a coherent memory description as well as memory for other people and activity declined markedly. Memory for location and source of the news (other person or media) was better preserved, but even in these cases the mean memory scores that were slightly higher than 1 indicated that this knowledge was not highly specific or exact. For example, a subject at retest might remember that he/she had originally "been at home watching the television" when learning of the resignation. This contrasts with the high degree of specificity of the original response, which might have been "at home in the living room watching the 7 o'clock news on Channel 4." Such "general" responses in the non-FB group were common and by our scoring scheme gained only one point.

In a further analysis focusing on the pattern of error ${ }^{9}$ responses on the FBQ, we found evidence of the reconstruction of memory attributes and retrieval of the "wrong" memory. For the non-U.K. group these errors were widespread, with approximately one third of all responses counted as reconstructions or recall of the "wrong" memory. The nature of these errors closely corresponds to the types of errors also observed by Neisser and Harsch (1992). In the U.K. subject group, errors were rare and accounted for less than $3 \%$ of responses, with the memories in this group characterized by remarkable consistency and detail. More generally, FB memories in the U.K. group (and when these occurred, in the nonU.K. group) fit well with R. Brown and Kulik's (1977) account of FB memory reports containing detailed information concerning people, place, activity, source, and some "irrelevant" details not usually retained in autobiographical memories. Our subjects, who met the FB memory criteria, remembered details such as what they had for breakfast, what television program they had been watching, the exact words spoken by a university lecturer, the place where someone had written the news on a wall, and the name of the radio broadcaster whose show had been interrupted. Many of the subjects recalled even more specific details, such as "tying my shoelaces," "handing a $£ 5$ note to a ticket vendor at a London underground station," and "walking toward a mirror in a room as the news was announced on the radio." In short, the FB memories identified in our subjects appeared to have the "live" quality emphasized by Brown and Kulik. Furthermore, consistently recalling apparently "irrelevant" details strongly suggests that the subjects accessed an actual memory of the reception event, which had originally been formed at encoding.

One potential problem is that only $85.6 \%$ of the U.K. group were classified as having FB memories. It is possible that this occurred because some of the subjects did not form FB memories during the reception event. On the other hand, it could be that memories in the U.K. group were, in general, not durable, as indicated by an annual forgetting rate of $14.4 \%$. If this estimated forgetting rate is correct, then only about $75 \%$ of our U.K. sub- 
jects should have FB memories 2 years after the resignation; after a retention interval of 10 years, few of our subjects would be able to recall the reception event. This constrasts with R. Brown and Kulik's (1977) finding that virtually all of their subjects had FB memories for the news of J.F.K.'s assassination many years after the event. We decided to check on the extent of forgetting by retesting a further wave of subjects. It was not feasible to retest all of our subjects, but we were able to retest 33 of them after a delay of 26 months. (Note that these data are not included in the analysis reported below.) Using the same scoring criteria, we found that only 2 of these 33 subjects failed to have FB memories-a forgetting rate of $6 \%$ to $7 \%$ per year. Moreover, only 1 of these subjects had been classified as having an FB memory at the 11-month interval. The two non-FB memory subjects chose not to guess, and in response to FBQ items simply wrote "I don't remember." These data, then, further demonstrate the durability of FB memories over lengthy periods of time.

In summary, the analyses of the memory attribute data show that the subjects with FB memories gave highly consistent and detailed memory descriptions over a period of 11 months, suggesting that the members of this group had highly specific and enduring memories. In contrast, the subjects who did not have FB memories gave incomplete and inconsistent memory descriptions over the 11month retention interval. The data suggest that members of this group had fragmentary memories that were not highly detailed and specific. Thus, the subjects in the non-FB group showed all the signs of individuals who are in the process of forgetting or who have already forgotten the reception event in which they learned of Thatcher's resignation.

\section{Secondary Measures}

The secondary measures were designed to assess two major components that are thought to influence FB memory formation-encoding and rehearsal. Three subgroups of measures-affect, importance, and knowledgeallowed us to examine factors influencing encoding, and three measures of rehearsal allowed us to examine factors operating after encoding. ${ }^{10}$ The central purpose of this section is to examine variations in FB and non-FB memories as a function of points on each of the rating scales, so the rating scales are analyzed by means of 2 $\times 3$ chi-squares. Note that 3-point rating scales were employed: $1=$ high, $2=$ moderate, and $3=$ low (see Table 1). Thus, FB memories (the between-subjects factor) formed two levels, and each rating scale (the withinsubjects factor) formed three levels of the chi-squares (in these analyses, $d f=2$ unless otherwise stated). The proportions of FB and non-FB memory subjects falling on each point of the rating scales are shown in Table 1. Affect was assessed by ratings of the intensity of experienced emotion and the extent of a subject's surprise upon learning of the resignation. The distribution of FB and nonFB memories across the rating scales differed significantly for both intensity $\left(\chi^{2}=23.98, p<.01\right)$ and surprise
Table 1

Proportion of FB and Non-FB Subjects Giving High, Moderate, and Low Ratings on Each of the Secondary Variables

\begin{tabular}{|c|c|c|c|c|c|c|}
\hline \multirow[b]{2}{*}{ Variables } & \multicolumn{3}{|c|}{ FB Memories } & \multicolumn{3}{|c|}{ Non-FB Memories } \\
\hline & High & Moderate & Low & High & Moderate & Low \\
\hline \multicolumn{7}{|l|}{ Affect } \\
\hline Intensity & .219 & .531 & .250 & .078 & .454 & .468 \\
\hline Surprise & .566 & .359 & .075 & .390 & .475 & \\
\hline \multicolumn{7}{|l|}{ Importance } \\
\hline PI & .167 & .605 & .228 & .057 & .404 & .539 \\
\hline NI & .715 & .254 & .031 & .482 & .468 & .5 \\
\hline \multicolumn{7}{|c|}{ Prior knowledge } \\
\hline Knowledge & .101 & .618 & .281 & .014 & .383 & .603 \\
\hline Interest & .201 & .659 & .140 & .106 & .575 & .31 \\
\hline \multicolumn{7}{|l|}{ Rehearsal } \\
\hline Thought & .070 & .793 & .137 & .000 & .425 & .575 \\
\hline Spoke & .044 & .666 & .290 & .000 & .345 & .645 \\
\hline Watched & .123 & .746 & .131 & .035 & .517 & .448 \\
\hline
\end{tabular}

Note-PI $=$ personal importance, $\mathrm{NI}=$ national importance.

$\left(\chi^{2}=11.51, p<.01\right)$. It can be seen from Table 2 that the largest proportions of FB memories are associated with high to moderate levels of intensity and surprise. NonFB memories, however, are associated with moderate to low levels of intensity and moderate levels of surprise. The importance variables, PI (personal importance) and NI (national importance), were also both significant $\left(\chi^{2}=\right.$ $39.4, p<.01$, and $\chi^{2}=20.2, p<.01$, respectively), and from Table 2 it can be seen that FB memories are associated with moderate levels of PI and high levels of NI. In contrast, non-FB memories are associated with moderate to low levels of PI and are equally distributed across the 3-point rating scale for NI. Ratings of both knowledge of Thatcher's government and interest in politics for FB and non-FB memories produced reliable differences $\left(\chi^{2}=41.2, p<.01\right.$, and $\chi^{2}=19.1, p<.01$, respectively). FB memories were associs..ed with moderate amounts of prior knowledge and a moderate level of interest in politics. Non-FB memories were associated with low levels of prior knowledge and moderate to low general interest in politics.

Two other measures, not shown in Table 1-other memories and politics-were also included in the knowledge/interest group. Other memories were scored as 0 for no memories, and 1 when any memories were named. These data were analyzed in a one-way ANOVA. The subjects with FB memories spontaneously and reliably recalled more "other memories" than did those without FB memories $\left[F(1,367)=16.6, M S_{\mathrm{e}}=4.0, p<.001\right.$; $M \mathrm{~s}=.56$ and .34 , respectively]. The subjects recalled between one and four other memories that, after examination of the protocols for the FB memory group, were classified into memories featuring political events, personal autobiographical events only, and those featuring both types of events. The distribution of other memories across these categories was as follows: political events $44 \%$, autobiographical events $18 \%$, and mixtures of both types of events $38 \%$. For the U.K. subjects, the political 
events that were recalled all related to occurrences during Margaret Thatcher's 11 years in power. The subjects in the non-U.K. group tended to recall more contemporaneous political events such as current wars and other political changes, particularly in Eastern Europe. Thus, the subjects with FB memories were often spontaneously reminded (in Schank's, 1982, sense) of other events; when this occurred, the recalled items were usually political events, and for the U.K. subjects they related directly to Thatcher's political career. It seems possible that this spontaneous recollection of related events may indicate the integration in memory of the resignation with other knowledge of Thatcher's years in power. Such integration might facilitate the stabilization in long-term memory of knowledge structures representing thematic aspects of the political period dominated by Prime Minister Thatcher (N. Brown, 1990).

For the three measures of rehearsal, the subjects judged how often they had thought or spoken about the resignation and how often they had attended to media reports that were either directly about the resignation or associated with it (referred to as "watched"). The rehearsal data were analyzed with the mixed-model chi-square; Table 1 shows the proportions of FB and non-FB memories falling at each point on the rating scales. All three measures of rehearsal produced significant effects (for thought, $\chi^{2}=83.2$; for spoke, $\chi^{2}=48.5$; and for watched, $\chi^{2}=$ $48.6 ; p<.01$ in all three cases). These differences arose because FB memories were rated as receiving moderate levels of rehearsal, whereas non-FB memories received moderate to low levels of rehearsal.

Finally, we briefly mention the analysis of the confidence ratings that had been collected for responses to Part 2 of the FBQ. The subjects used a 3-point scale in which $1=$ certain, $2=$ fairly sure, and $3=$ guess. Here we focused on subjects' confidence in their accuracy of remembering at retest the following attributes: people, place, activity, and source. Note that each variable was analyzed separately and FB memory (FB vs. non-FB) was used as a grouping factor in one-way ANOVAs. The reason for separate analyses was simply that some of the subjects could not remember some of the variables at times and, obviously, could not provide confidence ratings for these items. A highly significant effect of FB memory was observed for people $\left[F(1,327)=84.4, M S_{\mathrm{e}}=27.5, p<\right.$ $.001, \epsilon^{2}=.203$ ], and the subjects with FB memories were reliably more confident in the accuracy of their answer than were those who did not have FB memories; the respective means were 1.26 and 1.87 . The same pattern of very high confidence for the FB memory group and significant lower confidence for the non-FB memory group was present for the other three attributes [mean values were place 1.1 (FB) vs. 1.7 (non-FB), $F(1,356)=$ $84.4, M S_{\mathrm{e}}=29.96, p<.001, \epsilon^{2}=.236$; activity 1.27 (FB) vs. 1.9 (non-FB), $F(1,346)=84.4, M S_{\mathrm{e}}=30.96$, $p<.001, \epsilon^{2}=.197$; and source 1.1 (FB) vs. 1.6 (nonFB), $F(1,353)=84.4, M S_{\mathrm{e}}=20.83, p<.001, \epsilon^{2}=$ .202 ]. Thus, the subjects with FB memories were highly confident in the accuracy of their memories, and those without FB memories were reliably less confident, although by and large they did not guess. Note that this mean moderate level of confidence in the non-FB group reflects the fact that by far the majority of these subjects were, in fact, correct for at least some of the four memory attributes sampled in Part 2 of the FBQ.

In summary, then, the subjects with FB memories experienced more affect, perceived the event to be more important, knew more about the Thatcher administration, and were more interested in politics than those who did not form FB memories. Also, the FB memory group rehearsed the event more frequently than did the non-FB memory group, but rehearsal was generally at moderate to low levels. Levels of rehearsals were slightly higher on the thought and watched scales than the spoke scale (see Table 1). The subjects with FB memories were virtually certain of the accuracy of their memories, whereas those without FB memories were less confident.

\section{The Roles of Encoding and Rehearsal in Flashbulb Memory Formation}

Table 2 shows the intercorrelations between the primary and secondary variables. Note that the primary variable is the categorization of memory scores into FB memories (scores of .9 and 1) and non-FB memories (score of .8 or less) ${ }^{11}$ Correlations higher than $r=.11(d f=367)$ were significant at the $5 \%$ level, and it can be seen that only politics failed to correlate significantly with the other secondary variables. In order to analyze these data, we

Table 2

Correlation Matrix of FB Memory Scores With Secondary Variables

\begin{tabular}{|c|c|c|c|c|c|c|c|c|c|c|c|c|}
\hline & 1 & 2 & 3 & 4 & 5 & 6 & 7 & 8 & 9 & 10 & 11 & 12 \\
\hline 1. FB score & 1 & & & & & & & & & & & \\
\hline 2. Intensity & .240 & 1 & & & & & & & & & & \\
\hline 3. Surprise & .140 & .430 & 1 & & & & & & & & & \\
\hline 4. Personal importance & .300 & .384 & .208 & 1 & & & & & & & & \\
\hline 5. National importance & .167 & .234 & .218 & .468 & 1 & & & & & & & \\
\hline 6. Other memories & .182 & .251 & .099 & .212 & .095 & 1 & & & & & & \\
\hline 7. Knowledge & .331 & .364 & .211 & .379 & .192 & .303 & 1 & & & & & \\
\hline 8. Interest & .173 & .326 & .144 & .372 & .200 & .202 & .517 & 1 & & & & \\
\hline 9. Politics & .117 & .040 & .027 & .083 & .010 & .052 & .075 & .081 & 1 & & & \\
\hline 10. Rehearsal/thought & .443 & .283 & .206 & .447 & .213 & .247 & .426 & .360 & .081 & 1 & & \\
\hline 11. Rehearsal/watched & .296 & .190 & .191 & .339 & .225 & 172 & .329 & .256 & .060 & .479 & 1 & \\
\hline 12. Rehearsal/spoke & .165 & .105 & .018 & .166 & .027 & .120 & .142 & .162 & .042 & .283 & .288 & 1 \\
\hline
\end{tabular}

Note-Correlations in bold are significant, $p<.05$. 
conducted a series of hierarchical regressions by using sets of variables representing encoding and rehearsal (see Cohen \& Cohen, 1975, chap. 4). The main finding, however, was that although both the encoding and rehearsal sets were reliably associated with FB memory, they were also intercorrelated with each other. ${ }^{12}$ Thus, in order to specify the pattern of interrelations between these sets of variables in a more integrated and detailed manner, we decided to adopt a causal modeling approach.

For this analysis we used the structural equation approach of Bentler (see Bentler, 1980, 1989; Bentler \& Weeks, 1980). Note that the variable politics, which had low intercorrelations with the other variables, was omitted from these analyses. The strategy we adopted was as follows. A causal model of the secondary ratings for the FB memory group was developed; the model was then applied to the secondary ratings for the non-FB memory group. It was reasoned that if $\mathrm{FB}$ memories are not a unique class of memories, but rather represent an unusually detailed and durable set of "ordinary" memories (McCloskey et al., 1988), then the pattern of structural relations between the secondary ratings of FB and nonFB memories should be identical or, at the very least, highly similar. On the other hand, if FB and non-FB memories are completely disjunct classes of memories, then different constructs and different relations between constructs should underlie the formation of these classes of memories. A third possibility is that the same constructs are associated with the formation of both types of memories, but that relations between constructs differ. In line with our earlier reasoning and with the findings of the preceding section, we expected differences in the structural relations of affect and importance across the two sets of ratings.

We commenced the analysis with the model used in the regression analyses. There were two latent factors in this model: encoding and rehearsal. The encoding factor included the following variables: intensity (INT), surprise (SUR), PI, NI, other memories (O-MEMs), prior knowledge (KNO), and interest in politics (INT-P). The rehearsal factor comprised the following rehearsal variables: thought (THO), watched (WAT), and spoke (SPO). Variants of this two-construct model, with and without directional paths, were fitted to the data. However, the model and its variants did not provide a good fit. All chi-squares resulting from the model and its variants were significant, indicating that, statistically, models of this class are significantly discrepant from the data. The problem with this type of model is that the variables constituting the encoding factor are intercorrelated, and models that treat encoding as a single latent variable are not sensitive to these relations.

Accordingly, we generated a new class of models in which the subsets affect, importance, and knowledge/interest formed latent factors, replacing the encoding factor. Explorations with this class of models led to the model shown in Figure 3, which is a statistically excellent fit to the data [nonsignificant $\chi^{2}(22)=22.4, p>.66$ ] and a comparative fit index of 1.0. (Note that the comparative fit index runs from 0 to 1 , with values close to 1 in-

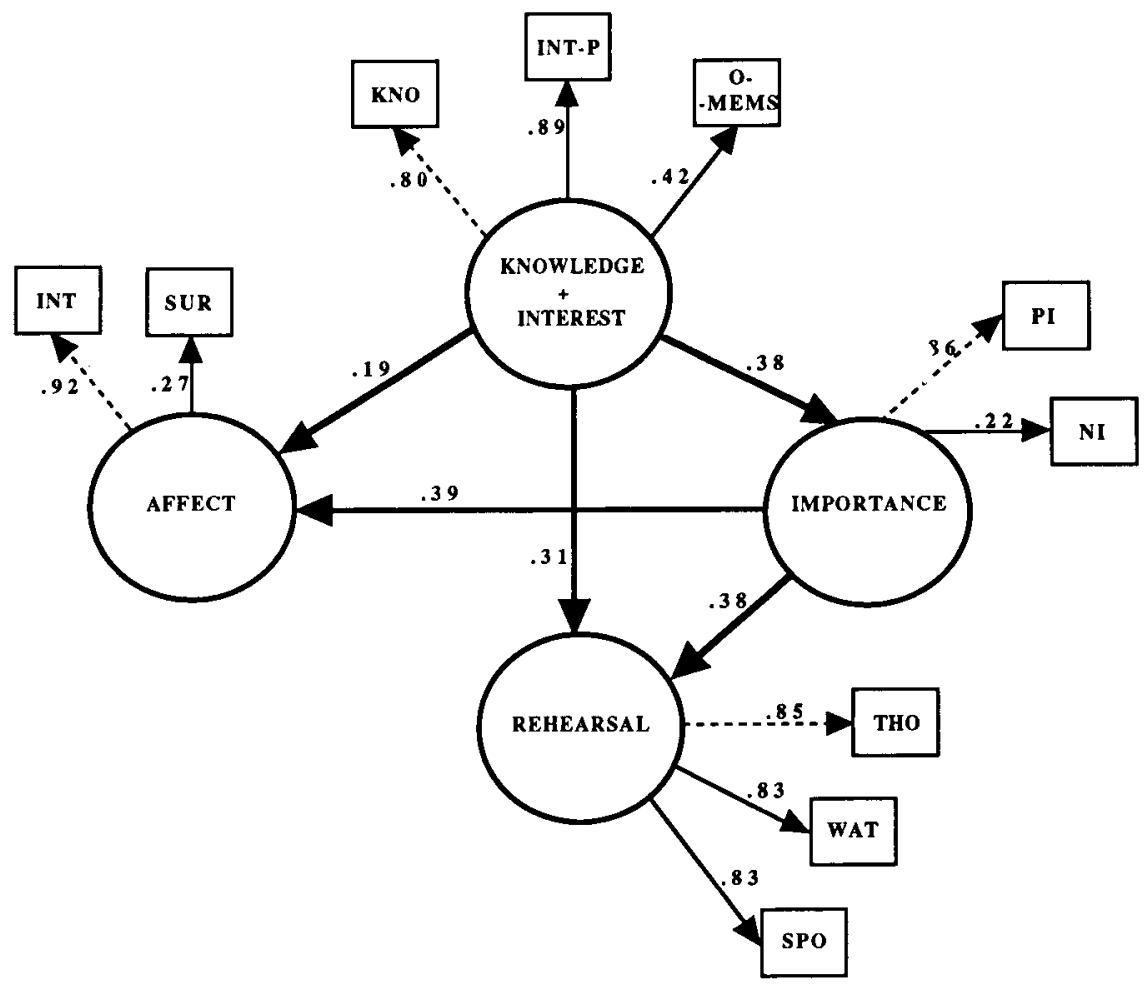

Figure 3. Causal model of the relations of the secondary variables to FB memories. Dashed lines denote fixed paths. All paths are significant, $p<.05$. See text for details. 
dicating good fit. See Bentler, 1989, for further details of fit indices.)

In Figure 3, latent constructs are shown in the circles and measured variables are in the squares. All the paths between the latent constructs are positive and significant. Arrows originating at one construct and terminating at another indicate that the originating construct contributes to the determination of the variance of the terminating construct. So, for example, the knowledge/interest construct directly contributes to the variance of the rehearsal construct, and on this path the value of .31 is the correlation of knowledge/interest with rehearsal. Note that because of this structural relation, knowledge/interest also makes an indirect contribution to the actual measures of rehearsal, shown in the paths from the rehearsal construct to the measured variables.

Consider the paths between knowledge/interest and the other three constructs. It is clear from Figure 3 that the knowledge/interest construct is central to FB memories in that this construct contributes significantly to all other constructs and, hence, indirectly to all measured variables. The greater the degree of knowledge/interest, the higher the levels of importance, affect, and rehearsal. Importance, too, is positively associated with levels of affect and rehearsal, so that the more important an event, the greater the affect and extent of rehearsal. Affect and rehearsal, however, were not directly associated or reciprocally related to knowledge/interest and importance. Thus, for FB memories, knowledge/interest and importance determine the degree of affect and extent of rehearsal.
When the model shown in Figure 3 was fitted to the non-FB memory secondary ratings, a chi-square was observed $\left[\chi^{2}(26)=45.1, p<.01\right]$, indicating a significant discrepancy between the model and these data. It was found that the two paths leading from the importance construct to the affect and rehearsal constructs were not significant, and the correlations fell to .042 and .068 , respectively. Thus, the critical difference between the FB and non-FB memory secondary ratings was in the role of importance and its structural relation to the other constructs. One other path was also nonsignificant-the path from the rehearsal construct to the observed variable "watched" $(r=.1)$. This is not surprising because most, but not all, of the non-FB subjects were from the U.S.A. group, who had rated themselves as having comparatively little media exposure to the news of the resignation (see Table 1).

A new model that omitted the three nonsignificant paths was then applied to the non-FB memory secondary ratings and a good fit was observed $\left[\chi^{2}(22)=27.2, p>\right.$ .20 ; comparative fit index of .977]. Figure 4 shows the non-FB model, where it can be seen that affect, importance, and rehearsal are independent constructs with no structural relations to each other. As with the FB memory group, the knowledge/interest construct was again found to be related to each of the other three constructs.

Next, consider the similarities between FB and non-FB secondary ratings. It can be seen from Figures 3 and 4 that both types of memories involve the same latent constructs and, by inference, the same encoding and rehearsal processes. Moreover, knowledge/interest plays a sim-

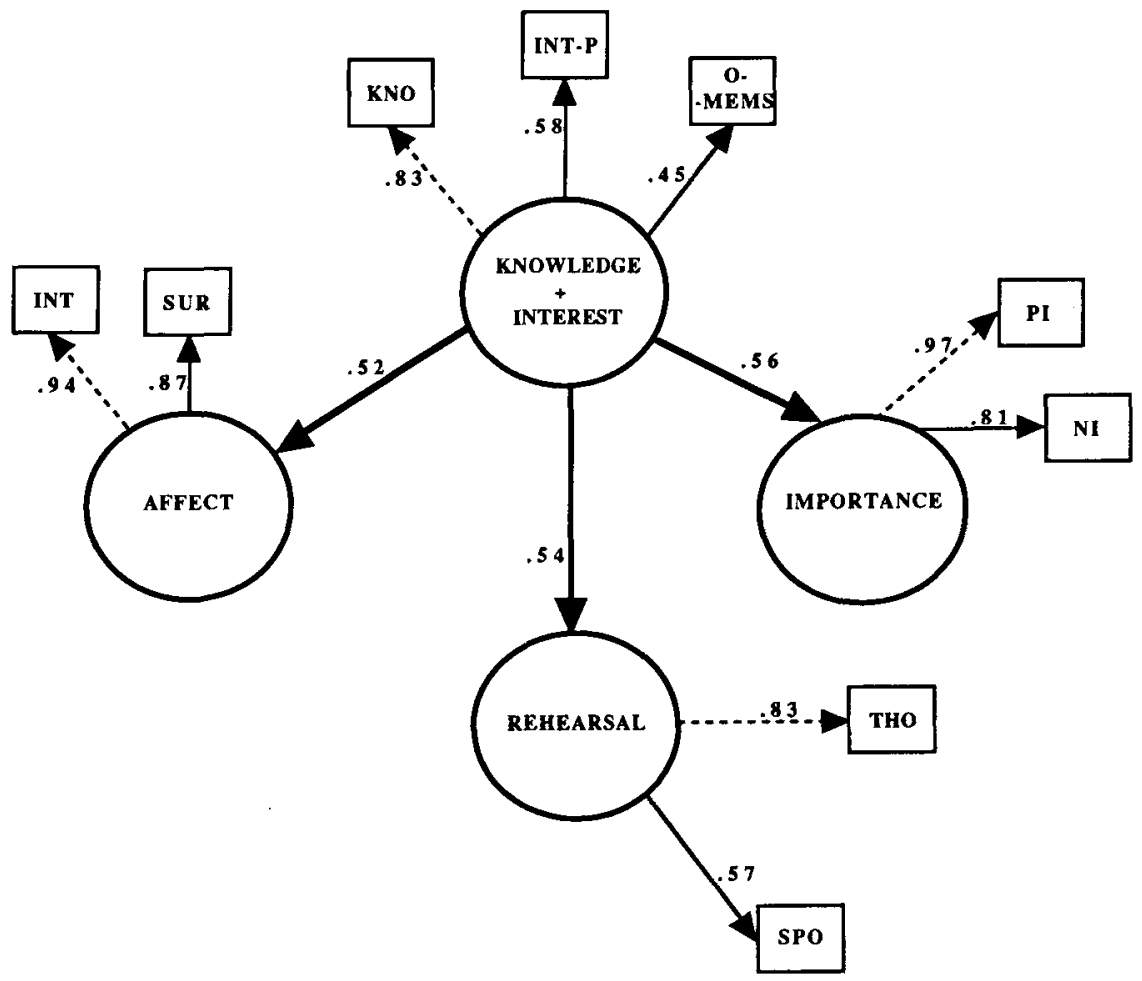

Figure 4. Causal model of the relations of the secondary variables to non-FB memories. Dashed lines denote fixed paths. All paths are significant, $p<.05$. See text for details. 


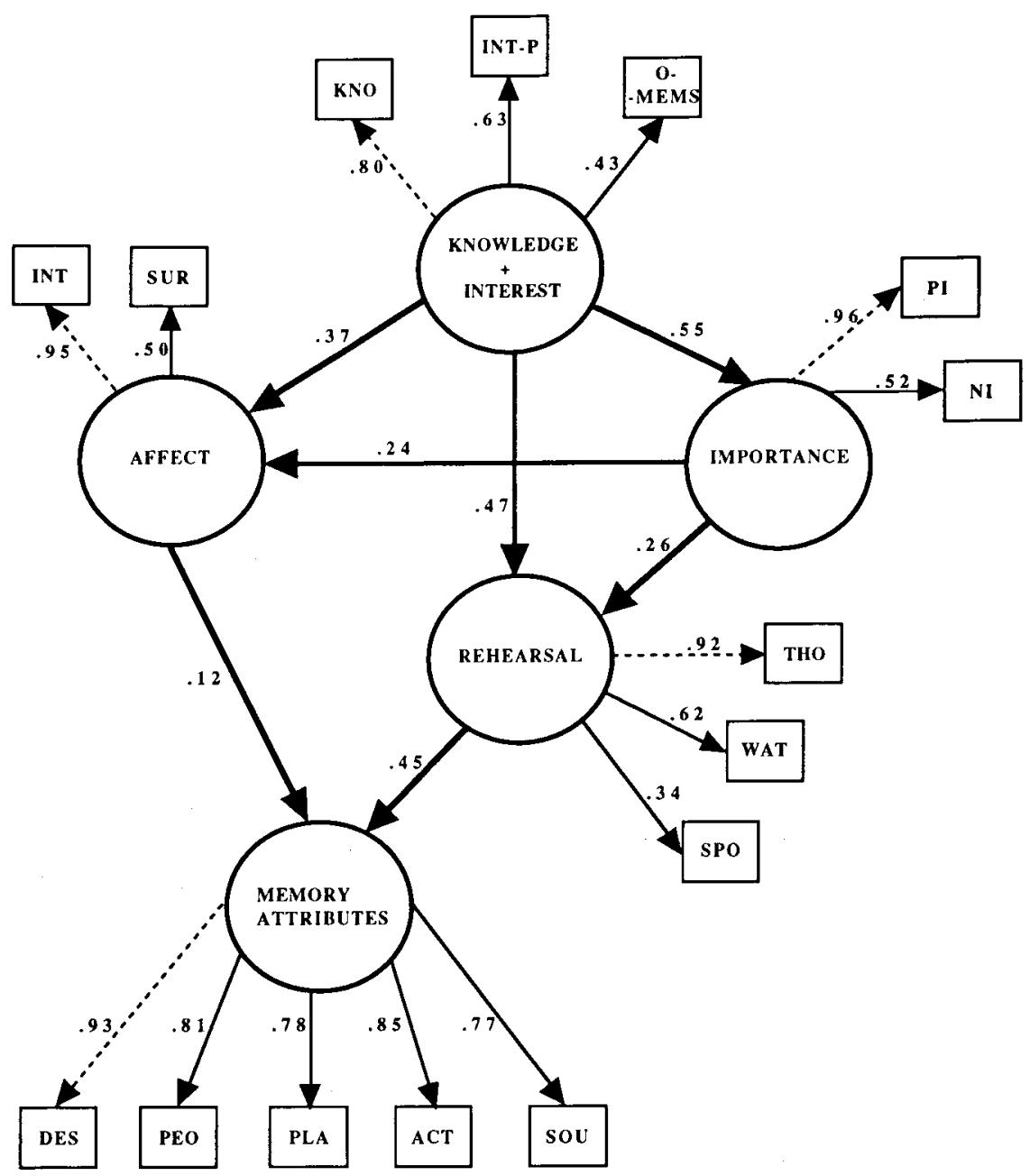

Figure 5. Causal model of the relations of the secondary variables to memory formation. Dashed lines denote fixed paths. All paths are significant, $p<.05$. See text for details.

ilar general role for both types of memories and is positively associated with affect, importance, and rehearsal. These findings suggest that some processes are common to the formation and maintenance of both FB and non-FB memories. Perhaps the processes associated with the knowledge/interest construct are common to the formation of all types of autobiographical memories and principally reflect the integration of new memories with preexisting knowledge in memory. The critical difference between the two models hinges on the role of the importance construct, which influences affect and rehearsal for FB memories but not for non-FB memories. This key difference is predicted by R. Brown and Kulik's (1977) account of FB memory formation and is compatible with broader studies of vivid memories (Rubin \& Kozin, 1984). Finally, we computed a full model across both sets of secondary ratings, plus the additional latent construct memory attributes calculated from the memory scores to the five memory attributes: memory description (DES), people (PEO), place (PLA), activity (ACT), and source
(SOU). Figure 5 shows the best-fitting model $\left[\chi^{2}(88)=\right.$ $106.2, p>.09$; comparative fit index of .991]. In this model, the effects of knowledge/interest and importance on FB memories are indirect and operate through the affect and rehearsal constructs to which they directly contribute. The striking feature in Figure 5 is that there are only two direct influences on the memory attributes construct; these are from the affect and rehearsal constructs. This part of the model shows that the higher the degree of affect and the more extensive the rehearsal, the more detailed the memory. There are no direct or indirect paths between affect and rehearsal, so it seems that the processes underlying these constructs may have separate effects on memory formation.

\section{DISCUSSION}

The striking finding of the present study was the high incidence of very detailed memory reports provided by the U.K. subjects, which remained consistent over an 11- 
month retention interval and, for a smaller group, over a 26-month retention interval. Memory for verbal and pictorial materials assessed under laboratory conditions typically decreases over a period of hours and days and rarely persists for periods longer than 1 month. Similarly, autobiographical memory for routine everyday events appears to rapidly decline (Brewer, 1988; White, 1982) and most people simply cannot remember events such as what they had for breakfast 11 months ago or the joke made by the lecturer in last year's philosophy seminar. Moreover, most items of news are quickly forgotten; for the few items that are retained, people rarely remember the personal circumstances under which they learned the news (Larsen, 1992). Against this background, FB memories clearly are an exception, enduring for long periods of time and retaining the types of details that are rapidly lost from "ordinary" everyday memories. Our findings indicate that a number of factors are influential in the formation and maintenance of FB memories; of these, the importance of the original event appears to be critical.

R. Brown and Kulik (1977, Figure 1, p. 83) proposed a process account of FB memory formation in which the effects of different sets of processes unfold over the period of the reception event. They summarized their process model in a schematic flow chart; in Figure 6 we provide a similar summary of the present findings. The main features of Figure 6 are based on the analyses of the structural relations between the secondary variables (see Figures 3 and 4). The same constructs were present in the FB and non-FB secondary ratings, so it is assumed that the same processes operate in the formation of both types of memories. The differences lie in the strength of encoding processes and in the structural relations between these process. Table 2 shows that subjects who eventually form FB memories have more detailed prior knowledge and are more likely to be reminded of related events than those who do not have FB memories. These findings suggest that FB memory subjects may be more able, or more prepared, to assimilate the news and its context (the reception event) to preexisting knowledge structures in memory. Similarly, the FB memory subjects had higher levels of affect and judged the event to be more important than those without FB memories. These differences in the strength of the relations between different encoding processes and memory types are shown in Figure 6 by the "greater" and "lesser" dimension attached to each of the constructs.

The arrows in Figure 6 depict the direction of relations between the constructs and show the way in which a set of processes associated with one construct influences the processes of another related construct. The dashed arrows show a route for the formation of ordinary, non-FB mem-

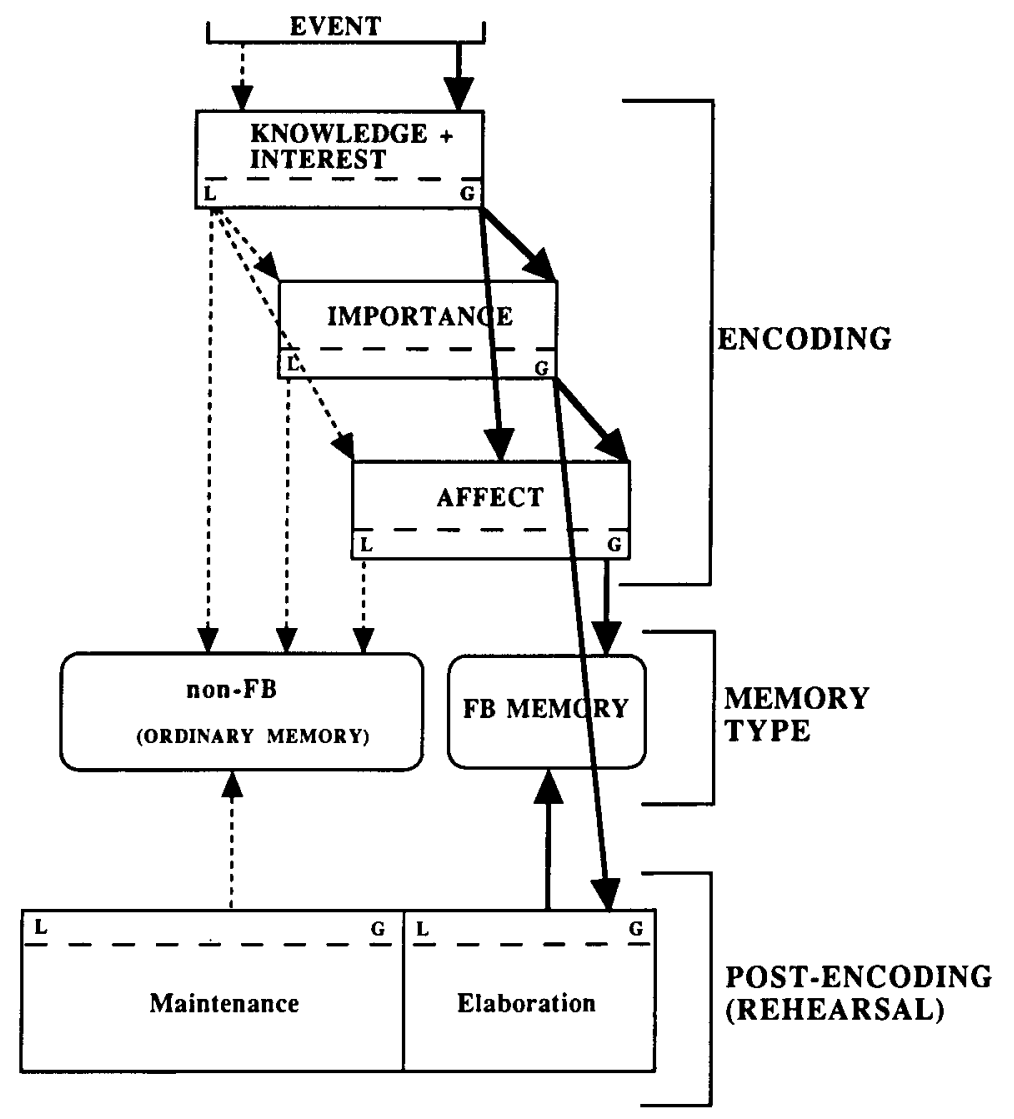

Figure 6. Sequence of encoding and rehearsal processes in memory formation and maintenance. $\mathbf{L}=$ lesser; $\mathbf{G}=$ greater. 
ories. The main proposal for the non-FB memories is that different sets of processes can make independent contributions to memory formation. Prior knowledge and interest are related to importance and affect, but they can mediate memory formation independently. For example, an event of little or no personal importance associated with only minimal levels of affect may nonetheless be encoded into long-term memory in terms of the knowledge structures employed in the processing of that event. We assume that this is the minimum that is required for the formation of any memory. Additionally, an event judged to be personally or nationally important may come to be encoded in terms of the self (Conway \& Rubin, 1993) and/or cultural knowledge (N. Brown, 1990). Finally, an event may be comparatively unimportant, but nevertheless engender some level of affect and so facilitate encoding. These relatively independent effects of the encoding constructs must also be present in the formation of FB memories. In this case, however, our findings indicate that in addition to the independent effects of the encoding constructs, there are also more integrated and coordinated effects. In particular, the construct of importance becomes associated with and influences affect and rehearsal (see Figure 3). The relation between importance and affect is shown by the additional dark arrow on the "greater" path in Figure 6 and represents a structural difference (rather than just a quantitative difference) in the formation of $\mathrm{FB}$ compared with non-FB memories.

In Figure 6, then, the formation of a memory is viewed as the culmination of a sequence of processes operating over time, either separately or in conjunction. The first set of processes features the utilization of prior knowledge (knowledge + interest, in Figure 6); these processes are common to the formation of all memories (see Figures 3 and 4). A second set of processes then evaluates the importance of the event, and a third set nediates the experience of affect in response to event features. When importance is high and comes to be associated with affect, then FB memories are formed. R. Brown and Kulik (1977) proposed that importance had to either reach or exceed levels of "biological significance," which we interpret as meaning that the item of news has to be judged as having consequences for self that are more significant than the consequences typically assigned to most items of news. This was certainly the case for the majority of the U.K. subjects in the present study, for whom the resignation of Prime Minister Margaret Thatcher represented the end of an era in British politics. If, however, importance does not reach some putative critical level, then an association between affect and importance is not present and these processes have separate effects on memory formation. In the present study, this latter case was found to lead to the formation of non-FB memories.

Not shown in Figure 6 are the direct effects of prior knowledge on rates of rehearsal, which were present for both FB and non-FB memories. Rehearsal rates were, in fact, very low for the non-FB group (mean ratings $>2.6$, indicating that many of the subjects did not rehearse the event) and at only moderate levels for the FB group (mean ratings $>2.1$ ). Nevertheless, this aspect of the findings demonstrates that the subjects with greater prior knowledge were more likely to think and talk about the resignation and more likely to follow media reports of the resignation than were the subjects with lower levels of prior knowledge and interest; this was the case irrespective of type of memory (see Figures 3 and 4). For the FB memory group only, there was also an additional effect of importance on rates of rehearsal (see Figure 6). It is possible that this effect reflects the greater general availability of FB memories in memory. Perhaps memories of important events are accessed comparatively frequently in the period following the reception event because of their associations with currently self-relevant themes, plans, and goals. It is even feasible that this association between importance and rehearsal may reflect some differential consolidation of FB compared with non-FB memories. Certainly the FB memory subjects indicated that they "thought" about the resignation more frequently than did the non-FB memory subjects (see Table 1).

Finally, as indicated in Figure 6, we tentatively suggest that rehearsal serves different functions for different types of memories. For "ordinary" non-FB memories, it is proposed that the main role of rehearsal is in preventative maintenance, which acts to preserve the fragmentary knowledge of the event, which is represented by nonFB memories. In the case of FB memories, it is proposed that the main effect of rehearsal is in the elaboration of FB memory reports. Such elaboration could function to establish multiple access routes to an FB memory and in this way expand accessibility and raise availability. Overall, however, it seems unlikely that rehearsal is critical to FB memories. This is because the smaller group of U.K. subjects, retested for a second time after a retention interval of 26 months, had a mean rehearsal rating of slightly more than 2.8 , indicating that they had not rehearsed the news. The majority of these subjects had FB memories, so a low level of continuous rehearsal cannot be essential to their maintenance.

The findings of the present study establish that the personal and national importance of an item of news is critical to FB memory formation. This can be seen in the different incidence of FB memories for the U.K. and non-U.K. groups and in the integrative and strong role of importance to FB memories, compared with its independent and weak role in non-FB memories. In these respects, our findings support R. Brown and Kulik's (1977) original proposal that some events, because of their consequentiality, give rise to unusually detailed memories. Moreover, although the encoding of both FB and non-FB memories features similar sets of processes, these processes are more integrated in the formation of FB than non-FB memories; in this sense the formation of FB memories might be considered to be special or privileged.

\section{REFERENCES}

Alvey, N. G., et AL. (1983). GENSTAT: A general statistical programme. Oxford, England: The Numerical Algorithms Group. 
Bentler, P. M. (1980). Multivariate analysis with latent variables: Causal modelling. Annual Review of Psychology, 31, 419-456.

BENTLER, P. M. (1989). EQS: Structural equations programme manual. Los Angeles: BMDP Statistical Software.

BENTLER, P. M., \& WEeKS, D. G. (1980). Linear structural equations with latent variables. Psychometrika, 45, 289-308.

BohanNON, J. N. (1988). Flashbulb memories for the space shuttle disaster: A tale of two theories. Cognition, 29, 179-196.

Brown, N. (1990). Organization of public events in long-term memory. Journal of Experimental Psychology: General, 119, 297-314.

Brown, R., \& Kulux, J. (1977). Flashbulb memories. Cognition, 5. 73-99.

BREWER, W. F. (1988). Memory for randomly sampled autobiographical events. In U. Neisser \& E. Winograd (Eds.), Remembering reconsidered: Ecological and traditional approaches to the study of memory (pp. 21-90). Cambridge: Cambridge University Press.

BREWER, W. F. (1992). An analysis of the theoretical and empirical status of the flashbulb memory hypothesis. In E. Winograd \& U. Neisser (Eds.), Affect and accuracy in recall: Studies of flashbulb memories" (pp. 274-305). Cambridge: Cambridge University Press.

Christianson, S. A. (1989). Flashbulb memories: Special, but not so special. Memory \& Cognition, 17, 435-443.

COHEN, J. \& COHEN, P. (1975). Applied multiple regression/correlation analysis for the behavioural sciences. Hillsdale, NJ: Erlbaum.

Conway, M. A., \& Rubin, D. C. (1993). The structure of autobiographical memory. In A. E. Collins, S. E. Gathercole, M. A. Conway, \& P. E. Morris (Eds.), Theories of memory (pp. 103-137). Hove: Erlbaum.

KEPPLE, G. (1982). Design and analysis: A researcher's handbook (2nd ed.). Englewood Cliffs, NJ: Prentice-Hall.

LARSEN, S. F. (1988). Remembering without experiencing: Memory for reported events. In U. Neisser \& E. Winograd (Eds.), Remembering reconsidered: Ecological and traditional approaches to the study of memory (pp. 326-354). Cambridge: Cambridge University Press.

LARSEN, S. F. (1992). Potential flashbulbs: Memories of ordinary news as the baseline. In E. Winograd \& U. Neisser (Eds.), Affect and accuracy in recall: Studies of "flashbulb memories" (pp. 32-64). Cambridge: Cambridge University Press.

MCCloskeY, M., Wible, C. G., \& Cohen, N. J. (1988). Is there a special flashbulb-memory mechanism? Journal of Experimental Psychology: General, 117, 171-181.

Neisser, U., \& HarsCh, N. (1992). Phantom flashbulbs: False recollections of hearing the news about Challenger. In E. Winograd \& U. Neisser (Eds.), Affect and accuracy in recall: Studies of flashbulb memories" (pp. 9-31). Cambridge: Cambridge University Press.

Pillemer, D. B. (1984). Flashbulb memories of the assassination attempt on President Reagan. Cognition, 16, 63-80.

Rubin, D. C., \& KozIn, M. (1984). Vivid memories. Cognition, 16, 81-95.

Schank, R. C. (1982). Dynamic memory. New York: Cambridge University Press.

WhITE, R. T. (1982). Memory for personal events. Human Learning, 1, 171-183.

\section{NOTES}

1. In the months preceding the resignation, Mrs. Thatcher's government had been in some trouble and senior figures had resigned, apparently in protest at her autocratic leadership and intransigence over key issues-but note that such resignations and dismissals had been a hallmark of her years in power. One particular ex-colleague was standing against her in an internal party reelection campaign, although this was widely perceived more as a continuation of internal protest within her party rather than as a serious challenge. Indeed, Mrs. Thatcher, in characteristic style, had announced less than $12 \mathrm{~h}$ earlier that "I fight on. I fight to win." At the time of her resignation, Mrs. Thatcher had been prime minister for 11 years and had presided over (indeed, had personally initiated) major controversial changes in British society. She had also led the the country through the Falklands War and appeared as a major figure in world politics. Her exceptionally cordial relationship with the American president Ronald Reagan had given her a high pro- file in North America, and her stance on the Cold War had led to prominence in European politics (at one time she was known as the "Iron Lady " for her opposition to the Soviet Union). Thus, the impact of the resignation was quite remarkable. Not only was it surprising (in the sense that it was wholly out of character and no one had expected her to resign, although the context was in place for her resignation), but it marked the end of an era in British politics and, to some extent, an end of an era in Anglo-U.S. politics, which had been dominated by strongly outspoken right-wing politicians for most of the 1980 s. U.K. media coverage of the resignation was intense and endured over a period of 3 to 4 days until attention gradually switched to the upcoming leadership contest for the recently vacated post of prime minister. In North America, media coverage was far less intense and lasted for a much shorter period, apparently receiving major portions of "air time" and headline space only on the day following the resignation. However, in the following weeks and months, Mrs. Thatcher herself was not particularly prominent in the media and kept a relatively low profile in the year immediately following her resignation. Nevertheless, she would certainly have been more prominent in the British media than in the media of other countries.

2. This retest group of subjects was drawn from a larger pool of subjects that had all been tested within 14 days of the resignation. In addition, a further large group was tested 11 months after the resignation. Memory perfomance in this latter group indicated that completing the FBQ within 14 days of the original event had no additional effect upon memory performance. A full account of this and all other details of the study, as well as results mentioned in the text but not fully reported, are available from the first author upon request.

3. Two questions that are not shown in Appendix A relate to the actual time and date of the original event and time and date of the reception event. For these questions the subjects were required to provide, as accurately as possible, the nearest minute, hour, day, month, and year of the original and reception events. The subjects were encouraged to guess. In the section on "feelings," the subjects were also asked to specify any emotion(s) they experienced during the reception event. Performance on these items does not relate directly to memory scores, so they are not reported further.

4. A final U.K. version of the FBQ was also administered at Lancaster to a group of second-year psychology undergraduates who completed the FBQ with reference to the Thatcher resignation and to a range of other outstanding public events, both political and nonpolitical, occurring in the U.K. close to the date of the resignation. Our aim was to identify a potential control event for the main study (Brewer, 1992). However, none of the events we sampled, other than the Thatcher resignation, were associated with FB memories; the subjects simply did not recall in detail their personal circumstances when learning of other political events, even those less than 1 week old (see Larsen, 1992). Moreover, although the events we had chosen had been given wide media coverage, many of the subjects (over $\mathbf{4 0 \%}$ ) claimed that they had not heard of these events prior to the pilot study. We concluded that although, in principle, memory for a control event would have been a desirable design feature, in practice, identifying an event that all subjects would initially know and have a memory for was simply not feasible.

On the basis of the pilot studies, various changes were made to the FBQ. In the pilot study, we found that some subjects experienced problems with the question concerning consequentiality of an event. This question was similar in wording to the one used by R. Brown and Kulik (1977), but our subjects often requested additional clarification prior to answering this question. We eventually established that two separate questions probing the personal and national importance of an event did not give rise to queries and, accordingly, in the final versions of the FBQ, the consequentiality question was replaced by the two importance questions (see also Rubin \& Kozin, 1984). The question relating to the status of Margaret Thatcher asked the U.K. subjects whether she had, in their opinion, been one of the best prime ministers of the century, an average prime minister, or a poor prime minister. For the non-U.K. subjects, this question was changed to read "Do you think Margaret Thatcher was a significant figure in international politics, a fairly average figure in international politics, or of no significance in international politics?" This change was introduced because the non-British students in our pilot study had found it difficult to answer the U.K. version of this question. However, in retrospect, this change was a mistake be- 
cause it regarded two different aspects of Mrs. Thatcher's career and confounded these with two different subject samples. Consequently, data from this question were not included in the analysis. A further change to the FBQ was to list the political parties appropriate to the country of the group to be sampled. In all other respects, however, the FBQ was the same for all the groups.

5. In fact, scores of .9 frequently arose because the memory description was marked as a 1 (see Figure 3), indicating a slightly more general description at retest than test. This finding should be treated with caution, because the subjects were not asked for exhaustive and detailed descriptions or instructed to write the same memory description at retest that they had written at test. The answers to the specific questions on people, place, activity, and source are undoubtedly better measures of memory consistency over the two tests. However, the ability to provide a coherent account of a past event is an important feature of memory, which is why we retained description as one of the FB memory attributes.

6. Note that $0.5 \%$ of the responses to the secondary variables were classified as missing cases, either because they were unreadable or because a subject had failed to respond to one of the questions. By far the largest number of missing cases occurred in response to the question on the valence of the reception event, which asked whether the experience was "good" or "bad." For the retest group, 30 responses (8\%) to this question were classified as missing cases. In retrospect, this was a poorly constructed question because a number of subjects wrote "neither" next to it or else left it blank. When the missing cases for valence were replaced and the variable was entered into the correlational analyses, valence was not found to be highly associated with either FB memories or other variables, so, consequently, we decided to omit this variable in the analyses. For the purposes of analysis, missing cases on the other variables were replaced by values that were calculated by using the expectation-minimization algorithm in the statistical package GENSTAT (Alvey et al., 1983).

7. An analysis of variance was used for this analysis because memory accuracy is a continuous rather than a categorical variable. Percentage of variance accounted for by each comparison is shown by $\epsilon^{2}$ (see Kepple, 1982, p. 92).

8. All contrasts were orthogonal planned comparisons.

9. A detailed account of the analysis of errors is available from the first author.

10. Additional analyses contrasting the same measures taken originally and at retest were also conducted. On some measures, the retest samples were slightly lower than the orig nal measures and the event was judged to be slightly less emotional and important at retest than it had been originally. For the rehearsal measures, the event was rated as being slightly, but reliably, less frequently rehearsed at retest than originally. This latter finding, however, may relate to a scaling problem. Originally, the subjects rated rehearsal with reference to a maximum period of 14 days, and less in many cases. Thus, they had judged frequency of rehearsal over a short period, but at retest the rehearsal ratings referred to a period of 11 months. It seems possible that these ratings may reflect a brief period of intense rehearsal followed by a longer period of sustained, but less intense, rehearsal. Because of this, the two types of rehearsal may not be directly comparable.

11. In fact, if the full scale of FB memory scores is entered into the correlational analysis, some of the correlations change. However, these changes are only slight and the effects reported in later multiple correlational analyses remain the same. We used the FB memory classification because we were interested in the differences between FB memories and non-FB memories rather than in a range of memories varying in FB memory qualities.

12. Details of these regression analyses are available from the first author.

APPENDIX A
Composition of the Flashbulb Memory Questionnaire
MEMORY ATTRIBUTES
Description*
People
Place
Activity
Source
ENCODING
1. Affect
Surprise $\dagger$
Intensity $\dagger$
Valence $\ddagger$
Emotion (named an emotion)
2. Importance
Personal importance (PI) $\dagger$
National importance (NI) $\dagger$
3. Knowledge/Interest
Other memories $\ddagger$
Knowledge of Thatcher's administration $\dagger$
Interest in Politics $\dagger$
Politics $§$
REHEARSAL
Times thought about $\dagger$
Times watched/read/listened to media
Times spoken about

*Score $0-2$, see text. †Rated on 3-point scale: $1=$ high, 2 $=$ moderate, 3 = low. \$Score 0 or 1 , see text. \$Score 1-3, see text.

\section{APPENDIX B \\ Examples of Memory Descriptions}

FB Memory Descriptions (Score .9-1)

\section{Subject A \\ TEST}

I wandered into my philosophy seminar and wondered what my tutor was smiling about.

When everyone had arrived, he announced "You've all heard about the Thatcher resignation have you?"

I was the only person there who hadn't. He then asked, "So what do you want to do, continue with the seminar or go and sit by your radios?"

RETEST

I staggered out of bed just in time to make it to a philosophy seminar. My tutor asked us if we had heard the news about Thatcher's resignation. 'Thatcher's resigned to what?' I asked. Which prompted a full explanation of the morning's events. He then asked whether we wished to have the seminar or go and sit by our radios. Amazingly, the group decided to have the seminar. 


\section{Subject B}

TEST

I first heard the news when I was in Dunbar Halls of residence at lunchtime. I was in the first-floor pantry of E. Block boiling water for a Pot Noodle when I caught the end conclusion of a TV news programme highlighting the resignation. There were two other people in the room whose faces I recall but I have never known their names.

RETEST

At the time I heard, I saw the news on television in a pantry in Dunbar Halls while I was about to have my lunch (Pot Noodle), just after one o'clock p.m. on that day.

\section{$\underline{\text { Subject } \mathrm{C}}$}

\section{TEST}

Biology lecture 12 midday on the day she resigned. Lecturer announced that we would be learning Krebbs' cycle and suggested we may remember it as we were learning it on the day Margaret Thatcher resigned. RETEST

At the beginning of Cell Biology lecture 12 midday. Lecturer announced that this was an important day since we were to learn the Krebbs' cycle and that Mrs. Thatcher had resigned. I was sitting on the left-hand side of the Arts lecture theatre. I was surprised at her resignation and asked several other people if this was true.

Subject D

TEST

I was in my room walking over to the mirror above my sink when I heard the news on the radio. RETEST

I was walking over from my desk towards my mirror in my room in Halls of residence when I heard on the radio that Margaret Thatcher had resigned.

$$
\text { Non-FB Memory Reports (Score < .9): Basically Accurate) }
$$

\section{Subject E}

\section{TEST}

It was during a biology lecture on cell respiration. We were about to start studying "Krebbs' Cycle" and the lecturer said that we would remember this always because we were learning it on the very day that Mrs. Thatcher resigned. A cheer resounded through the Arts Lecture theatre.

RETEST

I was in a biology lecture at the time-cell biology, I think-when the lecturer announced it. A cheer resounded through the lecture theatre-although one or two people shed a tear.

\section{Subject $\mathbf{F}$}

\section{TEST}

It was mid-morning and I came out of my room (having just got up) and I went into the kitchen. As I was in there my next door neighbour passed by and stopped to say hello. Then he said "Have you heard the news about Maggie?"' I was confused as to what he was talking about, then he explained that she had resigned and I can remember feeling very surprised.

\section{RETEST}

I was cooking my breakfast in the kitchen of the hall of residence that I was staying in. A friend came in and he told me that she had resigned.

Non-FB Memory Reports (Score 0): Incorrect

\section{$\underline{\text { Subject G }}$}

\section{TEST}

I was taking a study break in my dorm room and was switching the TV channels. It was on the news and I almost turned right past it. I finally figured out what was being said and realised what was going on.

RETEST

I was walking to class with my boyfriend and he brought it up. I couldn't believe that I hadn't heard; how cut off from the news I had been. I was surprised but when I thought about how many other countries were having a change in government I didn't find it that strange. 
$\underline{\text { Subject } \mathbf{H}}$

TEST

I was sitting next to a friend in Meston 4 when Dr. MacQuillan came in and said " I suppose by now you will have heard that Mrs. Thatcher has resigned. So if any of you want to be Prime Minister you can now put your names forward!" There was a general hubbub of chatter as everyone started to discuss the event. I said to my friend that I was really surprised that she had resigned, as I had expected her to fight to the bitter end. RETEST

Hear on Northsound Radio that Mrs. Thatcher had resigned before 2 nd round of voting between her and Mr. Heseltine, Hurd, and Major. Morning of a Thursday (I think). Making tea in kitchen (?)-No the above is not true. I think I heard from a friend in Psychology Class?-Hearing full story on radio came later-friend came into Psychology and told me.

(Manuscript received April 30, 1993;

revision accepted for publication July 23,1993 .) 